\title{
BEE FLIES, BLISTER BEETLES AND THE GRASSHOPPER CONNECTION
}

CEDRIC GILLOTT, TYLER J. WIST and JASON WOLFE, Department of Biology, University of Saskatchewan, 112 Science Place, Saskatoon, SK S7N 5E2. E-mail: gillott@duke.usask.ca

\section{Introduction}

In mid-June, 2003, I (CG) noticed many small (9-10 $\mathrm{mm}$ long), hairy, bumble beelike insects congregating on the flowers of my bedding plants. Commonly, there were several of these creatures on a single flower. By coincidence - or so it was initially thought - within a few days, I also saw that my spinach was infested with a small (7-10 $\mathrm{mm}$ long), reddish-brown to yellow beetle. Curiously, the beetles were concentrated on the male (pollen-bearing) spinach plants.

In early July, Tyler Wist and Jason Wolfe, while conducting a study of the pollination biology of narrow-leaved purple coneflower (Echinacea angustifolia), brought samples of the same insects to me for identification. They also were seeing large numbers on the coneflower flower heads., Densities of up to 17 bee flies and 4 blister beetles per head were observed. Often, both kinds of insects were found on the same head (see back cover photo). Reference to the Department of Biology insect collection confirmed that the bee-like insect was the grasshopper bee fly, Systoechus vulgaris, a species that is generally distributed across North America, ' while the beetle was the golden blister beetle, Epicauta ferruginea, which in Canada is found in the prairie provinces and Ontario. ${ }^{3}$

\section{Bee flies}

Despite their appearance, bee flies (Bombyliidae) are 'true' flies, that is, belong to the order Diptera. Some 800 species of bee flies have been recorded for North America, though the majority of these are restricted in distribution to sandy regions in the south-west of the continent. ${ }^{1,}{ }^{10}$ They range in length from 4 to $40 \mathrm{~mm}$. In addition to their hairiness, a striking feature of many species is a fearsome-looking 'stinger' that sticks out at the front and may be almost as long as the insect's body. This harmless structure is the proboscis, the insect's mouthparts, used to suck up nectar and ingest pollen. ${ }^{8}$ Like hover flies (Syrphidae; Diptera), with which they may easily be confused, bee flies often hover in mid-air, over flowers or patches of bare ground, before darting a few feet away for a repeat performance. Female bee flies lay their eggs in soil, and the larvae feed on a range of soil-dwelling insects, especially larvae of solitary bees and tiger beetles, and on grasshopper eggs.

\section{Blister beetles}

Some 310 species of blister beetles (Meloidae) occur in North America. ${ }^{1}$ Their common name derives from the observation that when disturbed, the beetles can exude body fluid from their joints. This fluid contains cantharidin, a toxic material that can cause blisters when rubbed on the skin. There have been frequent reports of livestock poisoning (even deaths in horses) after the animals fed on hay containing blister beetle corpses. ${ }^{2,4}$ For death to occur, however, large numbers of beetles would 


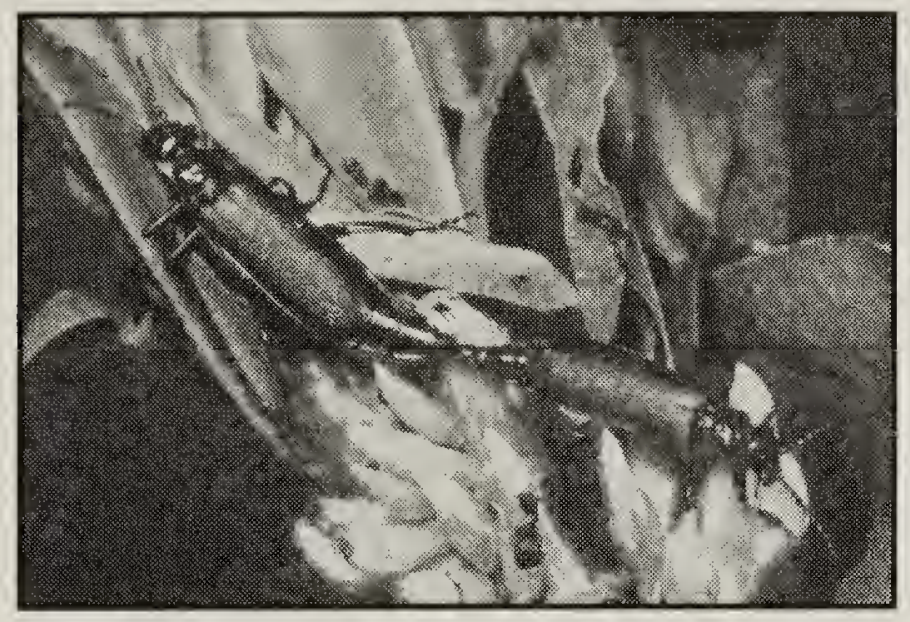

Figure 1. Mating Nuttall's blister beetles. Courtesy of Agriculture and Agri-Food Canada, Lethbridge Research Station.

have to be ingested (depending on the species of beetle, and the size of the horse, from 50 to 350$).{ }^{4}$ Such densities of blister beetles on forage crops are seen only in 'striped' species (e.g., Epicauta lemniscata and E. vittata) that form aggregations much like a honey-bee swarm. These do not occur in the Canadian Prairies. ${ }^{3}$

Blister beetles range in length from about 3 to $30 \mathrm{~mm}$. Probably, the species most familiar to readers is Nuttall's blister beetle (Lytta nuttalli), a large (20-28 mm) iridescent species with a dark green head, prothorax and abdomen, and purple elytra (Figure 1). Adults are commonly found from early June to early August, preferring to feed on legumes, especially caragana, alfalfa, clovers, lupines and vetches. Other species, including the golden blister beetle, are less choosy and will eat a wide range of wild and cultivated plants. Occasionally, they become pests of crops such as potatoes, tomatoes, sugarbeets and forages. ${ }^{10}$

Depending on the species, blister beetle larvae feed on bee larvae or grasshopper eggs. Female blister beetles of some species deposit eggs directly in bees' nests. Others place their eggs on plants from which the newly hatched larvae attach themselves to bees to be carried back to the host's nest. ${ }^{10}$ Those whose larvae feed on grasshopper eggs lay a batch of eggs in long cylindrical burrows they dig in soil. ${ }^{5}$ Given the long odds against finding a host in these circumstances, it is not surprising that an egg batch may comprise several hundred eggs. ${ }^{6}$

\section{Why so many, and is their abundance more than coincidence?}

In an average year a few grasshopper bee flies and golden blister beetles may be seen. So, why were there so many in the summer of 2003, and is there a link between the high numbers of the two species? We believe the answer to these questions rests in the fact that the two species have been sharing the same bed! The photograph on the back cover may suggest that the "bed" being shared is the flower head, more specifically, the pollen which is probably the major source of the protein necessary for egg production. However, we propose that the bed in question is a grasshopper egg bed, that is, the site where grasshoppers congregate to lay eggs. Females of both the grasshopper bee fly and the golden blister beetle lay their eggs in soil at grasshopper egg-laying sites.

In contrast to the eggs of most prairie grasshoppers, which lie dormant until the following spring, the bee fly and blister beetle eggs develop rapidly and soon hatch. On hatching, the highly mobile larvae actively search for grasshopper eggs on which to feed. During its development, a single larva of either species can destroy an entire egg pod (about 25 eggs) of smaller grasshoppers such as the clear-winged (Camnula pellucida) and lesser migratory (Melanoplus sanguinipes), or about half the eggs in the pod of the larger, two-striped grasshopper (M. bivittatus). ${ }^{10}$ By early fall, larvae are full-grown and molt to the pupal stage in which they pass the winter.

In recent years, a succession of warm, dry springs has been conducive to the development of huge grasshopper populations across the prairies. In the summer of 2002, two-striped and lesser migratory grasshoppers were especially 
abundant. We believe that the high numbers of grasshopper bee flies and golden blister beetles in 2003 reflect the high densities of grasshopper egg pods laid the previous year. Earlier studies have shown that a significant proportion of grasshopper egg pods are destroyed as a result of feeding by larval bee flies and blister beetles. Seventy years ago, Criddle noted that larvae of S. vulgaris, blister beetles and ground beetles destroyed $20 \%$ of the egg pods in Manitoba, with destruction reaching $90 \%$ in some regions. ${ }^{7}$ An extensive study in the U.S.A. showed that, on average, in predominantly cropland areas $15 \%$ of pods were destroyed by bee fly and blister beetle larvae. ${ }^{9}$ In North Dakota and Montana, the average was more than $25 \%$, with some areas experiencing almost $60 \%$ egg-pod destruction. ${ }^{9}$ Such figures confirm that bee fly and blister beetle larvae are important agents in the natural control of grasshoppers. In addition, the adults appear to play a significant role as pollinators of some high-value crops, for example, narrow-leaved purple coneflower. With grasshopper populations expected to remain high for some time, these highly distinctive predators may supplant the dog as 'Man's best friend'!

\section{Acknowledgement}

We thank Dr. Art Davis for his comments on a draft of the manuscript.
1. ARNETT, R.H. JR. 2000. American Insects: A Handbook of the Insects of America North of Mexico ( $2^{\text {nd }}$ edition). CRC Press, Boca Raton, FL.

2. BLODGETT, S., P.M. DENKE and V. KNERR. 2002. Blister beetles of Montana. Montana State University, Bozeman, MT. Montguide MT200209 AG.

3. BOUSQUET, Y. (ED.). 1991. Checklist of Beetles of Canada and Alaska. Agriculture Canada, Ottawa. Publication 1861/E.

4. CAPINERA, J.L., D.R. GARDNER and F.R. STERMITZ. 1985. Cantharidin levels in blister beetles (Coleoptera: Meloidae) associated with alfalfa in Colorado. Journal of Economic Entomology 78: 1052-1055.

5. CHURCH, N.S. 1967. The egg-laying behavior of 11 species of Lyttini (Coleoptera: Meloidae). The Canadian Entomologist 99:752-760.

6. CHURCH, N.S. and G.H. GERBER. 1977. Observations on the ontogeny and habits of Lytta nuttalli, L. viridana, and L. cyanipennis (Coleoptera: Meloidae): The adults and eggs. The Canadian Entomologist 109: 565-573.

7. CRIDDLE, N. 1933. Notes on the habits of injurious grasshoppers in Manitoba. The Canadian Entomologist LXV: 97-102.

8. DEYRUP, M.A. 1988. Pollen-feeding in Poecilognathus punctipennis (Diptera: Bombyliidae). Florida Entomologist 71: 597-605.

9. PARKER, J.R. and C. WAKELAND. 1957. Grasshopper egg pods destroyed by larvae of bee flies, blister beetles, and ground beetles. U.S.D.A. Tech. Bull. 1165 .

10. SWAN, L.A. and C.S. PAPP. 1972. The Common Insects of North America. Harper and Row, New York.

"A surprising spectrum of native invertebrates pollinates crop plants : midges, blowflies, soldier flies, syrphid flower flies, hawkmoths, nitidulid beetles, checkered beetles, ladybird beetles, fig wasps, sphecid and vespid wasps, sweat bees, squash and gourd bees, carpenter bees, andrenid bees, bumblebees, mason bees, lealfcutter bees, and cactus-loving bees." 